\title{
Lithium-mediated Ferration of Fluoroarenes
}

\author{
Lewis C. H. Maddocka, Alan Kennedy, and Eva Hevia*a
}

\begin{abstract}
While fluoroaryl fragments are ubiquitous in many pharmaceuticals, the deprotonation of fluoroarenes using organolithium bases constitutes an important challenge in polar organometallic chemistry. This has been widely attributed to the low stability of the in situ generated aryl lithium intermediates that even at $-78{ }^{\circ} \mathrm{C}$ can undergo unwanted side reactions. Herein, pairing lithium amide LiHMDS $\left(\mathrm{HMDS}=\mathrm{N}\left\{\mathrm{SiMe}_{3}\right\}_{2}\right)$ with $\mathrm{Fe}^{\prime \prime}(\mathrm{HMDS})_{2}$ enables the selective deprotonation at room temperature of pentafluorobenzene and 1,3,5-trifluorobenzene via the mixed-metal base [(dioxane)LiFe(HMDS) ${ }_{3}$ (1) (dioxane $=1,4$-dioxane). Structural elucidation of the organometallic intermediates [(dioxane)Li(HMDS) $\left.{ }_{2} \mathrm{Fe}(\mathrm{ArF})\right]\left(\mathrm{Ar}^{\mathrm{F}}=\mathrm{C}_{6} \mathrm{~F}_{5}, 2 ; 1,3,5-\mathrm{F}_{3}-\mathrm{C}_{6} \mathrm{H}_{2}, 3\right)$ prior electrophilic interception demonstrates that these deprotonations are actually ferrations, with Fe occupying the position previously filled by a hydrogen atom. Notwithstanding, the presence of lithium is essential for the reactions to take place as $\mathrm{Fe}^{\prime \prime}(\mathrm{HMDS})_{2}$ on its own is completely inert towards the metallation of these substrates. Interestingly $\mathbf{2}$ and $\mathbf{3}$ are thermally stable and they do not undergo benzyne formation via LiF elimination.
\end{abstract}

Keywords: Cooperative bimetallics · Deprotonative metallation · Fluoroarenes · Iron · Lithium

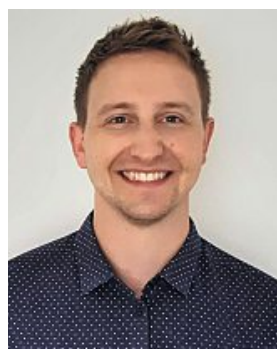

Lewis C. H. Maddock obtained his MSci in Pure and Applied Chemistry from the University of Strathclyde (UK), completing his final year project with Prof. Rab Mulvey. From 2012-2016 he carried out his PhD research on alkali-metal ferrate complexes at the same institution working with Prof. Eva Hevia. After two years of postdoctoral work concerning Single-Molecule Magnet ligand strategies with Prof. Richard Layfield at the Universities of Manchester and Sussex (UK), he returned to work with Prof. Hevia at the University of Bern. His current research focuses on cooperative bimetallics featuring Earth-abundant transition metals.

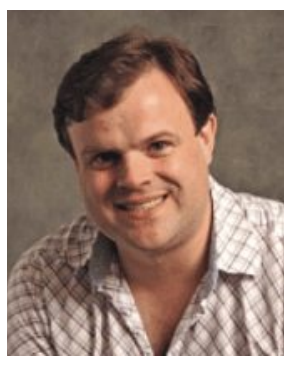

Alan Kennedy received both his BSc and $\mathrm{PhD}$ degrees in chemistry from the University of Glasgow, Scotland. The latter was under the tutorage of Drs Kenneth Muir and Ron Cross. A specialist in crystallography, he established the first single crystal diffraction facilities of the Dept. of Pure \& Applied Chemistry at the University of Strathclyde in the 1990s and has worked there ever since. His research centres on linking structure to chemical and physical properties - especially in the fields of $s$-block metal complexes, colourants and pharmaceuticals.

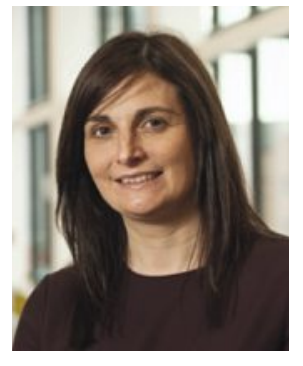

Eva Hevia received both her MSci degree in Chemistry and her PhD degree from the Universidad de Oviedo (Spain) in 1998 and 2002 respectively. After a three-year position at the University of Strathclyde (Glasgow, UK) working as a Marie Curie Fellow with Professor Robert Mulvey, in 2006 she took up a Royal Society University Research Fellowship and Lectureship there. Subsequently she was promoted to Full Professor in 2013. In February 2019, Eva moved to the University of Bern to take up a full professorship in Inorganic Chemistry. Research in her group focuses on polar organometallic chemistry at the crossroads of inorganic, organic, and green chemistry. Eva is an elected fellow of the European Academy of Sciences and her research has been recognised with several awards including the 2017 RSC Corday-Morgan Prize and the 2019 Organometallic Chemistry Award by the Spanish Royal Society of Chemistry.

\section{Introduction}

Amongst the different tools available for the functionalisation of aromatic molecules, Directed ortho-Metallation $(D o M)$ is arguably one of the most powerful and widely used in synthesis. ${ }^{[1-4]}$ Polar organometallics such as lithium amide LiTMP (TMP = 2,2,6,6-tetramethylpiperidide) or organolithiums RLi are usually the reagents of choice, ${ }^{[5-7]}$ although in many cases their applications can be compromised by their moderate selectivity and limited functional group tolerance. ${ }^{[8]}$ This is particularly challenging for the deprotonation of fluoroarenes. While highly electronegative, fluorine is a good ortho directing group, increasing the acidity of its neighbouring $\mathrm{H}$ atoms. The main limitation is the lack of stability of the metallated intermediates generated (e.g. benzyne formation, autometallation and cascade processes), ${ }^{[9]}$ as illustrated by Schlosser in a seminal study on the deprotonation of 1,3,5-trifluorobenzene by ${ }^{t} \mathrm{BuLi} .{ }^{[10]}$ To address some of these challenges and considering the prominent role of fluoroarenes in pharmaceutical synthesis, where around $20-25 \%$ of forthcoming drugs contain at least one F atom, ${ }^{[11,12]}$ several alternative $s$-block organometallic strategies have been developed using single-metal bases but also mixed-metal reagents. This includes the use of 
lithium zincates developed by Uchiyama ${ }^{[13]}$ which generate more stable arylzinc intermediates, that can be subsequently quenched, enabling the metallations to take place at room temperature. Magnesiation of fluoroarenes has also been accomplished under mild reaction conditions employing magnesium bases supported by the bulky $\beta$-diketiminate ligand which provides steric protection to the highly reactive fluoroaryls. ${ }^{[14]} s$-Block metals can also work in tandem with main-group metals, as shown for the deprotonation of fluoroarenes using LiTMP in combination with $\mathrm{Ga}\left(\mathrm{CH}_{2} \mathrm{SiMe}_{3}\right)_{3}$ (via trans-metal-trapping (TMT) approaches), ${ }^{[15,16]}$ where the lithium amide metalates the substrate while the gallium alkyl traps and stabilises the sensitive carbananion, which can subsequently be employed in Pd-catalysed $\mathrm{C}-\mathrm{C}$ bond forming processes. ${ }^{[17]}$ Along with these main-group-metal-mediated strategies, Knochel has used the trimetallic combination (TMP) $)_{2} \mathrm{Fe} .2 \mathrm{MgCl}_{2} .4 \mathrm{LiCl}$ for the functionalisation of a range of fluoroarenes via deprotonative metallation followed by $\mathrm{Ni}$ catalysed cross-coupling with alkyl halides. ${ }^{[18]}$ In this study ortho-ferration of the aromatic substrates was proposed, although the constitutions of the organometallic intermediates involved remained undetermined.

Inspired by these studies, we have recently investigated the metallating ability of iron(II) bis(amide) $\mathrm{Fe}^{\mathrm{II}}$ (HMDS), (HMDS $\left.=\mathrm{N}\left\{\mathrm{SiMe}_{3}\right\}_{2}\right),{ }^{[19]}$ which is isostructural in the solid state with the parent $\mathrm{Mg}$ (HMDS) ${ }_{2}{ }^{[20]}$ Interestingly, while on its own this compound fails to deprotonate fluoroarenes, when partnered with group 1 amide NaHMDS and forming sodium ferrate [(dioxane $)_{0.5} \mathrm{NaFe}(\mathrm{HMDS})_{3}$ ], we can perform regioselective direct ferration of a variety of fluoroarenes under mild conditions, a rare example where Fe can perform a metallation reaction. ${ }^{[21]}$ These studies hinted at a crucial effect of the alkali metal, acting as a facilitator that ultimately leads to the direct $\mathrm{Fe}-\mathrm{H}$ exchange process, which appears to be directed by the initial coordination of the substrate to sodium. Thus, these reactions can be described as alkali-metal-mediated ferrations $(A M M F e){ }^{[15]}$ Extending the scope of this approach to other $s$-block metals, here we investigate the synthesis of a heterobimetallic lithium-iron base and assess its reactivity towards fluoroarene metallation.

\section{Results and Discussion}

\subsection{Synthesis of Mixed-Metal Amide Base 1}

Akin with our reported studies on sodium ferrates, ${ }^{[21,22]}$ we began with the monometallic HMDS compounds LiHMDS and $\mathrm{Fe}(\mathrm{HMDS})_{2}$, which were combined in hexane, quickly forming a homogeneous light green solution at ambient temperature (Scheme 1). To this mixture, 1 eq. of 1,4-dioxane was added resulting in the precipitation of a pale green solid which could be crystallised after solubilising in fluorobenzene and cooling to $-30{ }^{\circ} \mathrm{C}$. X-ray crystallographic analysis revealed the structure of [(dioxane) $\left.\mathrm{LiFe}(\mathrm{HMDS})_{3}\right](\mathbf{1})$ which could be recovered in a $70 \%$ yield (Fig. 1).

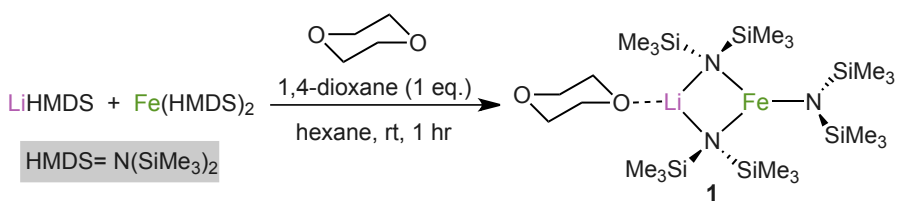

Scheme 1. Synthesis of lithium ferrate base 1.

Heterobimetallic 1 exhibits a discreet contacted-ion pair structure, where $\mathrm{Li}$ and $\mathrm{Fe}$ are connected by two bridging HMDS amido groups with a further terminal HMDS residing on $\mathrm{Fe}$. Unsurprisingly the $\mathrm{Fe}-\mathrm{N}$ bond distances for the bridging amido groups are slightly elongated when compared to that of terminal

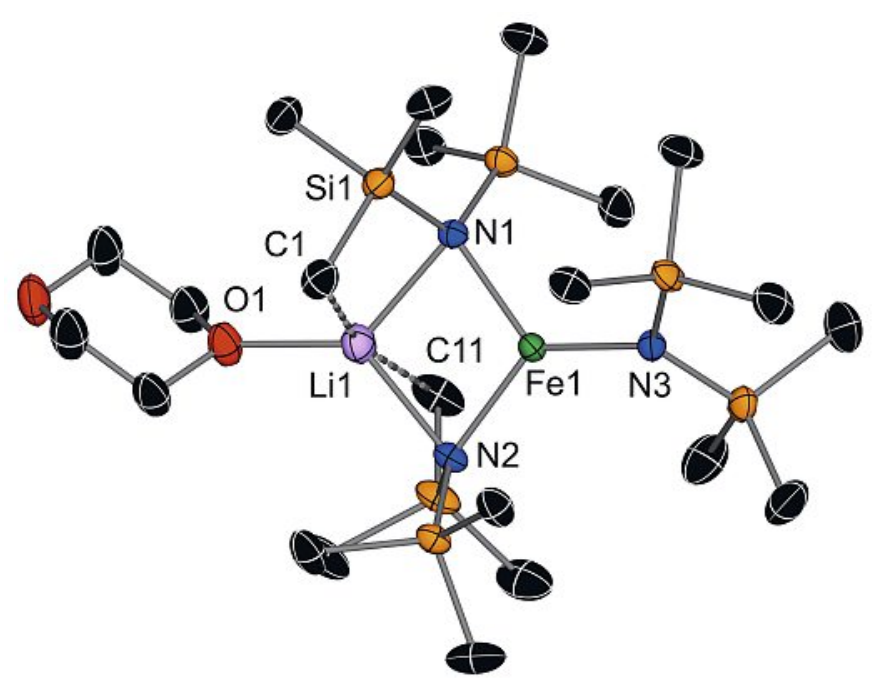

Fig. 1. Molecular structure of [(dioxane)LiFe(HMDS) $)_{3}$ (1). Hydrogen atoms omitted for clarity. Thermal ellipsoids displayed at $50 \%$ probability level.

HMDS [mean value 2.0511 vs 1.9604(19) Å]. Lithium completes its coordination sphere binding to a terminally coordinated molecule of 1,4-dioxane [Li1-O1 1.991(5) $\AA$ ] as well as forming two long-distance interaction with two methyl groups, each of them belonging to a different bridging $\mathrm{HMDS}$ ligand [ $\mathrm{Li} \cdots \mathrm{C} 1,2.785(5)$ and Li-C11, 2.829(5) А, shown as dashed bonds in Fig. 1]. Interestingly a comparison of the geometrical parameters of 1 with those previously reported by Layfield for its unsolvated congener $\left[\mathrm{LiFe}(\mathrm{HMDS})_{3}\right],{ }^{[23]}$ showed that while the coordination environment around $\mathrm{Fe}$ in both compounds is almost identical, the $\mathrm{Li}-\mathrm{N}$ bonds [mean values, 2.041 vs $2.134 \AA$ in 1 ] and $\mathrm{Li}^{\cdots} \mathrm{Me}$ electrostatic interactions [mean value $2.332 \AA$ ] are noticeably shorter for the latter. A similar trend was noted for the sodium analogue of $\mathbf{1}$, $\left[(\text { dioxane })_{0.5} \mathrm{NaFe}(\mathrm{HMDS})_{3}\right]$, ${ }^{21]}$ with almost identical $\mathrm{Fe}-\mathrm{N}$ bond distances to those witnessed in $\mathbf{1}$ but significantly elongated $\mathrm{Na}-\mathrm{N}$ distances [mean value, $2.464 \AA$ ], consistent with the larger size of $\mathrm{Na}$ (see Table 1 for details). No $\mathrm{Na} \cdots \mathrm{C}$ long distance interactions were observed for this complex which exhibits a dimeric structure, with dioxane bridging two $\left\{\mathrm{NaFe}(\mathrm{HMDS})_{3}\right\}$ fragments. [21] These bonding preferences ultimately translate to the $\mathrm{Li}$ atom being 'sunk' further into the steric sphere of the $\left\{\mathrm{Fe}(\mathrm{HMDS})_{3}\right\}^{-}$unit, in closer proximity to $\mathrm{Fe}$ at a distance of 2.665(4) $\AA$ (vs Na1---Fe1 2.9995(6) $\AA$ in the sodium ferrate complex, see Fig. 2 and Table 1). These structural features can be rationalised considering the anchoring/ancillary bonding model previously described by Mulvey for $s$-block heterobimetallic chemistry. ${ }^{[24]}$ Thus, the shorter and more covalent $\mathrm{Fe}-\mathrm{N}$ interactions can be described as anchoring bonds, providing the $\left\{\mathrm{Fe}(\mathrm{HMDS})_{3}\right\}^{-}$foundation units for these structures, to which the alkali metals (AM) are affixed by a combination of weaker $\mathrm{AM}-\mathrm{N}$ and $\mathrm{Li} \cdots \mathrm{CH}_{3}$ ancillary bonds.

The solution-phase effective magnetic moment of $\mathbf{1}\left(5.36 \mu_{\mathrm{B}}\right)$ was determined using Evans method, ${ }^{[26-28]}$ which is in the range of the spin-only magnetic moment value $(4.90 \mu)$ for a high-spin $(S=2) \mathrm{Fe}(\mathrm{II})$ centre. The paramagnetic ${ }^{1} \mathrm{H}$ NMR spectrum of $\mathbf{1}$ in $d_{8}$-toluene solutions displays three very broad resonances centred at $21.06,10.21$ and $-2.46 \mathrm{ppm}$. While the paramagnetic shifting and extensive broadening of these signals makes their assignment particularly challenging, ${ }^{[29]}$ a comparison of this spectrum with that recorded for $\left[\mathrm{LiFe}(\mathrm{HMDS})_{3}\right]$ (see Supporting Information) allows the assignment of the signal of 21.06 to the coordinated molecule of dioxane, whereas the resonances at 10.21 and -2.46 ppm are tentatively assigned to the terminal and bridging HMDS groups, respectively. This differentiation between terminal and bridging amide ligands is also present in $\left[\mathrm{LiFe}(\mathrm{HMDS})_{3}\right]$ (8.80 and $-2.20 \mathrm{ppm}$ respectively, see Supporting Information) but contrasts 
Table 1. Selected bond distances $(\AA)$ and angles $\left(^{\circ}\right)$ for complexes 1-3 $(\mathrm{AM}=\mathrm{Li})$ and $\left[(\operatorname{dioxane})_{0.5} \mathrm{NaFe}(\mathrm{HMDS})_{3}\right] .^{[21]}$

\begin{tabular}{|c|c|c|c|c|}
\hline & 1 & 2 & 3 & {$\left[(\text { dioxane })_{0.5} \mathrm{NaFe}(\mathrm{HMDS})_{3}\right]$} \\
\hline Fe1-N1 & $2.0474(19)$ & $1.990(4)$ & $2.007(3)$ & $2.0378(12)$ \\
\hline $\mathrm{Fe} 1-\mathrm{N} 2$ & $2.0548(18)$ & $2.009(3)$ & $2.017(3)$ & $2.0625(11)$ \\
\hline $\mathrm{Fe} 1-\mathrm{N} 3$ & $1.9604(19)$ & - & - & $1.9443(12)$ \\
\hline $\mathrm{Fe} 1-\mathrm{C} 13$ & - & $2.092(4)$ & $2.078(4)$ & - \\
\hline AM1-N1 & $2.133(5)$ & $2.098(8)$ & $2.080(8)$ & $2.4395(13)$ \\
\hline $\mathrm{AM} 1-\mathrm{N} 2$ & $2.135(5)$ & $2.141(9)$ & $2.135(8)$ & $2.4894(13)$ \\
\hline AM1-O1 & $1.991(5)$ & $1.954(9)$ & $1.943(8)$ & $2.2828(12)$ \\
\hline Fe1---AM1 & $2.665(4)$ & $2.649(8)$ & $2.661(7)$ & $2.9995(6)$ \\
\hline $\mathrm{N} 1-\mathrm{Fe} 1-\mathrm{N} 2$ & $103.41(8)$ & $103.96(14)$ & $102.72(13)$ & $109.17(5)$ \\
\hline $\mathrm{N} 1-\mathrm{Fe} 1-\mathrm{N} 3$ & $125.99(8)$ & - & - & $125.93(5)$ \\
\hline $\mathrm{N} 2-\mathrm{Fe} 1-\mathrm{N} 3$ & $130.39(8)$ & - & - & 124.91(5) \\
\hline N1-Fe1-C13 & - & $126.99(16)$ & $127.70(15)$ & - \\
\hline N2-Fe1-C13 & - & $129.05(16)$ & $129.57(14)$ & - \\
\hline N1-AM1-N2 & $97.93(18)$ & $96.0(3)$ & $96.4(3)$ & $85.36(4)$ \\
\hline
\end{tabular}

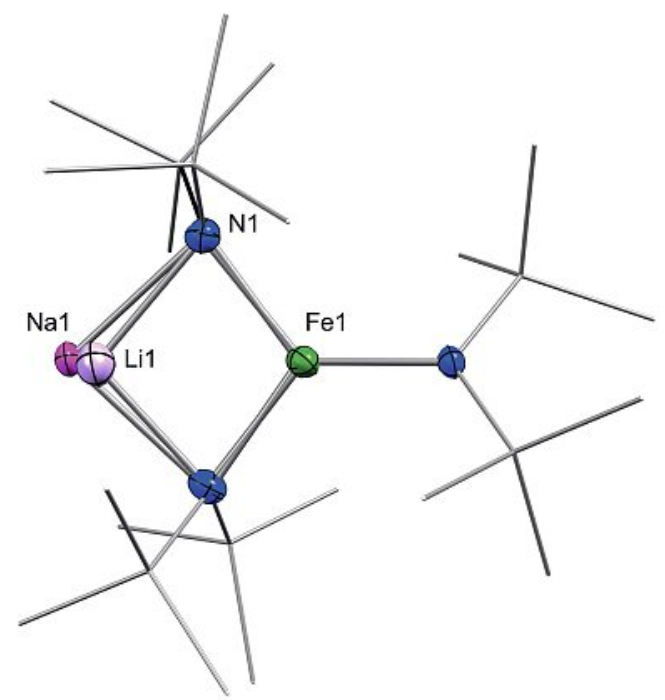

Fig. 2. Overlay of $\left\{\mathrm{MFe}(\mathrm{HMDS})_{3}\right\}$ structures of 1 and $[($ diox-

ane $\left.)_{0.5} \mathrm{NaFe}(\mathrm{HMDS})_{3}\right]^{[21]}$ Overlay of N1, Fe1 and N2 atoms in Mercury. ${ }^{[25]}$ $\mathrm{SiMe}_{3}$ units depicted as wires and a terminal HMDS group, solvating 1,4-dioxane groups and hydrogen atoms omitted for clarity.

with previous ${ }^{1} \mathrm{H}$ NMR spectra reported for related sodium ferrates where just a single broad signal is observed for the HMDS groups (Scheme 2). ${ }^{[21,22]}$ These spectroscopic findings correlate with the structural studies showing that $\mathrm{Li}$ is noticeably more embedded within the coordination pocket created by the $\left\{\mathrm{Fe}(\mathrm{HMDS})_{3}\right\}^{-}$anion than $\mathrm{Na}$ (Fig. 2). Assuming that the interconversion between bridging/terminal HMDS groups in these ferrates takes places via the initial cleavage of one AM-N $\mathrm{N}_{\text {bridging }}$ bond $(\mathrm{AM}=$ alkali metal), followed by rotation around the remaining $\mathrm{Fe}-\mathrm{N}_{\text {bridging }}$ bond and formation of a new $\mathrm{AM}-\mathrm{N}$ bond to close a four-membered $\{\mathrm{AMNFeN}\}$ ring (as depicted in Scheme 2), it should be expected for this fluxional process to be faster for $\mathrm{Na}$ than for Li. Accordingly, at room temperature all HMDS groups appear equivalent in the ${ }^{1} \mathrm{H}$ NMR spectrum for the sodium ferrate but for $\mathbf{1}$ two distinct signals for the terminal and bridging HMDS groups are observed.

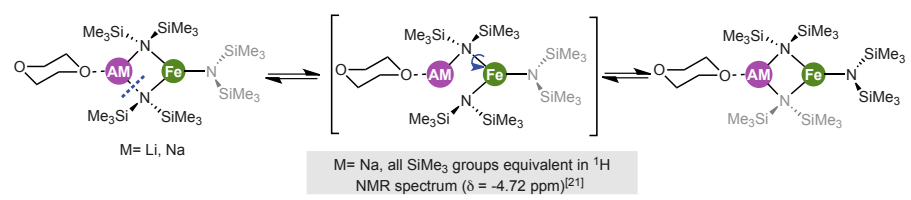

Scheme 2. Proposed fluxional process that interconverts bridging and terminal HMDS groups in alkali-metal ferrates [(dioxane) ${ }_{x} \mathrm{AMFe}(\mathrm{HMDS})_{3}$ ] $(A M=L i, x=1 ; A M=N a, x=0.5)$.

It should also be noted that when the ${ }^{1} \mathrm{H}$ NMR of $\mathbf{1}$ is carried out in the coordinating solvent $d_{8}$-THF, a single signal is observed for the HMDS groups at $-2.34 \mathrm{ppm}$ but in this case this is most likely due to the formation of a solvent-separated ion pair $\left\{\mathrm{Li}(\mathrm{THF})_{\mathrm{x}}\right\}^{+}\left\{\mathrm{Fe}(\mathrm{HMDS})_{3}\right\}^{-}$species. Nevertheless in both deuterated solvents, THF or toluene, the bimetallic constitution of $\mathbf{1}$ is preserved and no evidence was observed in solution for this lithium ferrate to be in equilibrium with its single-metal components $\mathrm{Li}(\mathrm{HMDS})$ and $\mathrm{Fe}(\mathrm{HMDS})_{2}$.

\subsection{Assessing the Metallating Ability of 1 towards Selected Fluoroarenes}

The reactivity of heterobimetallic amide $\mathbf{1}$ was probed using pentafluorobenzene and 1,3,5-trifluorobenzene as model substrates (Scheme 3). Reactions were carried out using benzene as a solvent, and stoichiometric amounts of the relevant fluoroarene. In both cases, they were accompanied by a distinctive colour change from pale green to brown, which occurs almost immediately as the relevant fluoroarene was introduced. Slow cooling of these solutions afforded [(dioxane) $\left.\mathrm{Li}(\mathrm{HMDS})_{2} \mathrm{Fe}\left(\mathrm{C}_{6} \mathrm{~F}_{5}\right)\right]$ (2) and [(dioxane) $\left.\mathrm{Li}(\mathrm{HMDS})_{2} \mathrm{Fe}\left(1,3,5-\mathrm{F}_{3}-\mathrm{C}_{6} \mathrm{H}_{2}\right)\right]$ (3) in $88 \%$ and $77 \%$ yields respectively (Scheme 3 ).

X-ray crystallographic studies established the molecular structures of $\mathbf{2}$ and $\mathbf{3}$ and demonstrated that these reactions are formally ferrations in which a strong Fe-C $\sigma$-bond is formed [2.092(4) $\AA$, $2 ; 2.078(4) \AA, 3]$. Interestingly the metallated fluroaryl binds terminally to iron and does not interact with the lithium centre which displays a similar coordination environment to that previously described for 1 (Figs 3 and 4 and Table 1 for further details). Denoting 


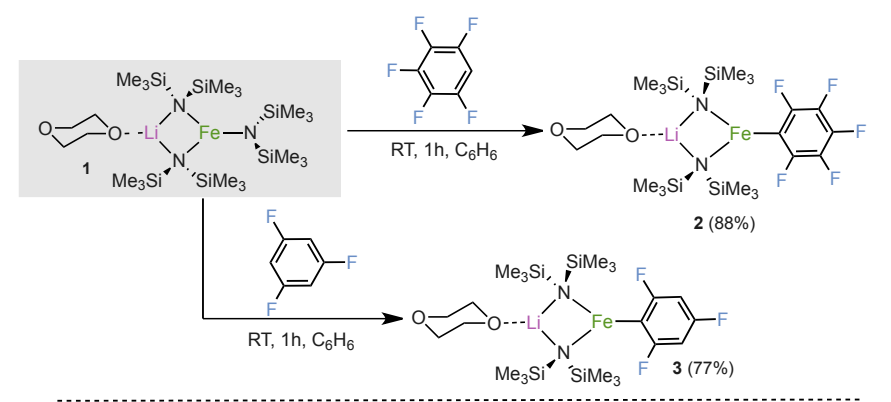

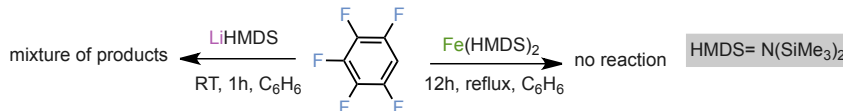

Scheme 3. Lithium mediated ferration of pentafluorobenzene and 1,3,5-trifluorobenzene by heterobimetallic tris(amide) base $\mathbf{1}$ to give 2 and 3 respectively.

a clear alkali-metal effect, the metal-coordination modes present in $\mathbf{2}$ and $\mathbf{3}$ contrast with those reported by us on the metallation of 1,3-difluorobenzene by [(dioxane $)_{05} \mathrm{NaFe}(\mathrm{HMDS})_{3}$ ] where the fluoroarene adopts a bridging disposition between $\mathrm{Na}$ and $\mathrm{Fe}$, with $\mathrm{Na}$ forming a dative bond with one of the fluorine atoms. These $\mathrm{Na} \cdots \mathrm{F}$ interactions have been proposed to direct the regioselectivity of the metallation and provide further stabilisation.

Compounds $\mathbf{2}$ and $\mathbf{3}$ were also characterised by ${ }^{1} \mathrm{H}$ NMR spectroscopy using $\mathrm{C}_{6} \mathrm{D}_{6}$. The spectrum of $\mathbf{2}$ shows a very broad resonance centred at $-2.69 \mathrm{ppm}$ corresponding to the HMDS groups and a much sharper resonance at $7.64 \mathrm{ppm}$ for the 1,4-dioxane protons. Similarly, for $\mathbf{3}$, a very broad resonance centred at -3.70 ppm is visible (HMDS) along with a much sharper signal at 9.79 ppm (1,4-dioxane). Located far downfield, an informative resonance at $105.60 \mathrm{ppm}$ integrating to two protons is also observed, corresponding to the aryl protons. Solution-phase effective magnetic moments of 4.98 and $4.53 \mu_{\mathrm{B}}$ for $\mathbf{2}$ and $\mathbf{3}$, respectively, were determined using Evans method, again corresponding to high$\operatorname{spin}(S=2) \mathrm{Fe}(\mathrm{II})$ centres.

Compounds $\mathbf{2}$ and $\mathbf{3}$ are stable in solution at room temperature and even at higher temperatures (refluxing in benzene for 6 hours) no decomposition is observed. This thermal stability is in sharp contrast with the marked fragility observed in lithiated fluoroaryls, where, in some cases, even working at $-78{ }^{\circ} \mathrm{C}$ fast decomposition could be observed. ${ }^{[10]}$ As shown in Scheme 3, the formation of $\mathbf{2}$ and $\mathbf{3}$ is truly synergistic in origin since none of the single components of the heterobimetallic base 1, LiHMDS or $\mathrm{Fe}(\mathrm{HMDS})_{2}$ can successfully selectively deprotonate pentafluorobenzene at room temperature on their own. Furthermore, while crystallographic studies establish unequivocally that these

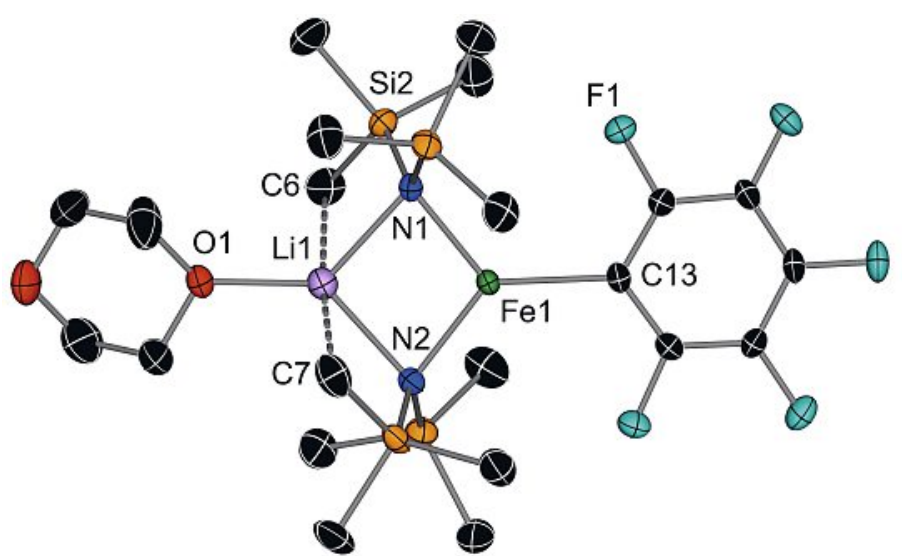

Fig. 3. Molecular structure of [(dioxane) $\left.\mathrm{Li}(\mathrm{HMDS})_{2} \mathrm{Fe}\left(\mathrm{C}_{6} \mathrm{~F}_{5}\right)\right](2)$. Hydrogen atoms omitted for clarity. Thermal ellipsoids displayed at $50 \%$ probability level.
$\mathrm{M}-\mathrm{H}$ exchange reactions are formal ferrations, the presence of lithium seems to be key to promote these metallations. Thus, these processes can be envisaged as lithium-mediated ferrations for the reactions with 1,3,5-trifluorobenzene, as shown in Scheme 4. As previously proposed for the heterobimetallic sodium-ferrate, ${ }^{[21]}$ a plausible mechanism may involve initial coordination of the fluoroarene to lithium which fixes the regioselectivity of the reaction (I in Scheme 4). This activates the substrate towards deprotonation by one of the bridging amido groups of $\mathbf{I}$, furnishing intermediate II in which the fluoroaryl is acting as a bridge between the two metals, binding to $\mathrm{Fe}$ through its metallated $\mathrm{C}$ and to lithium via one of its $\mathrm{F}$ atoms. Isomerisation of II via cleavage of the $\mathrm{Li} \cdots \mathrm{F}$ contact, followed by rotation around the remaining $\mathrm{Fe}-\mathrm{N}$ bond of the remaining bridging HMDS, enables the switching of the bridging/terminal positions of the aryl and HMDS groups in II, furnishing $\mathbf{3}$, which is the final product detected and structurally characterised (Fig. 4). This isomerisation step can be driven by the coordination preference of $\mathrm{Li}$ which prefers to strongly bond the two HMDS groups rather than just one of them and one of the F atoms of the metallated aryl (II in Scheme 4). Interestingly in the case of $\mathrm{Na}$, II is the final product of the reaction and no isomerisation step is observed.[21]

Related to these findings, anotherinteresting alkali-metal effect has been noticed for these reactions. Reacting 1,3,5-trifluorobenzene with two molar equivalents of [(dioxane $\left.)_{0.5} \mathrm{NaFe}(\mathrm{HMDS})_{3}\right]$ led to the 2,4-diferration of this fluoroarene, affording a thermally unstable intermediate that rapidly eliminates $\mathrm{NaF}$ when the temperature is raised to $60{ }^{\circ} \mathrm{C} .{ }^{[21]}$ Contrastingly, even when 1,3,5-trifluorobenzene is reacted with a 2 molar excess of $\mathbf{1}$,

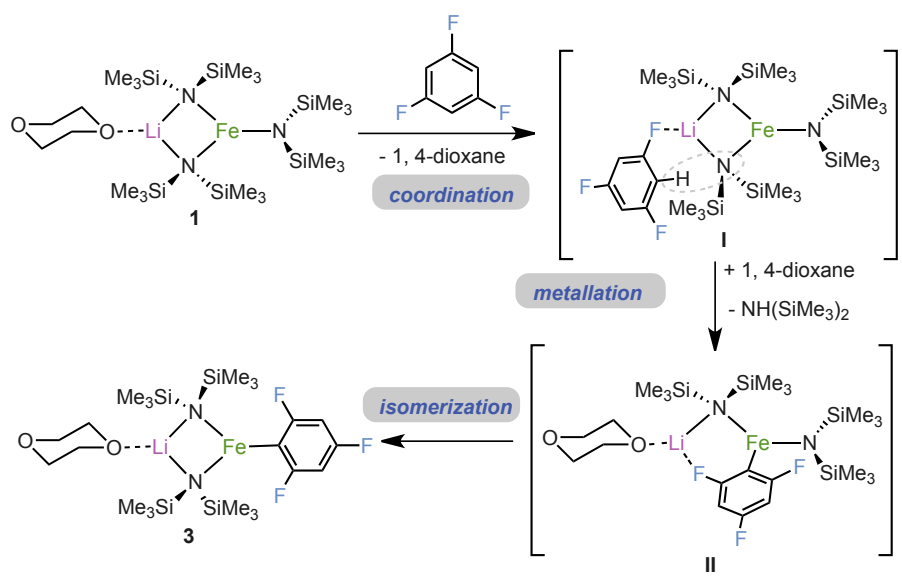

Scheme 4. Proposed mechanism for the lithium-mediated ferration of 1 , 3, 5-trifluorobenzene executed by 1 .

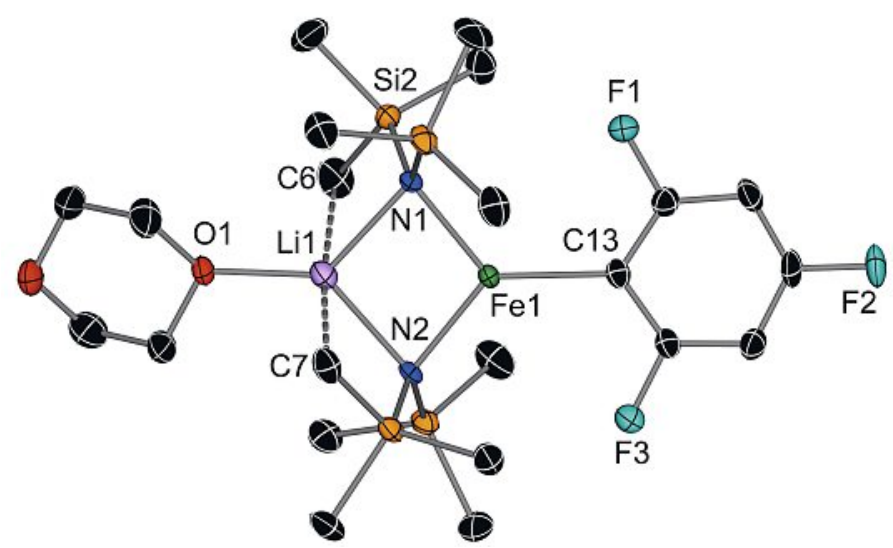

Fig. 4. Molecular structure of [(dioxane) $\left.\mathrm{Li}(\mathrm{HMDS})_{2} \mathrm{Fe}\left(1,3,5-\mathrm{F}_{3}-\mathrm{C}_{6} \mathrm{H}_{2}\right)\right](3)$. Hydrogen atoms omitted for clarity. Thermal ellipsoids displayed at $50 \%$ probability level. 
monoferrated species $\mathbf{3}$ is the only product obtained in the reaction, which is thermally robust and does not decompose at higher temperatures.

Interestingly many reactions of transition metal complexes with fluoroarenes seem to favour $\mathrm{C}-\mathrm{F}$ versus $\mathrm{C}-\mathrm{H}$ bond activation, especially for substrates that have a high degree of fluorination. ${ }^{[31]}$ In particular, work by Holland has shown that Fe(II) complexes can promote $\mathrm{C}-\mathrm{F}$ bond activation of perfluoroaromatics, including pentafluorobenzene ${ }^{[32]}$ and the same reactivity preference has also been noted for $\mathrm{Fe}(0)$ species. ${ }^{[33]}$ Contrastingly here, the cooperative partnership of $\mathrm{Li}$ and $\mathrm{Fe}$ enables chemoselective transformation of $\mathrm{C}-\mathrm{H}$ bonds into $\mathrm{C}-\mathrm{Fe}$ bonds, leaving the $\mathrm{C}-\mathrm{F}$ sites of the substrates intact. Reactions appear to be driven by the activation of the hydrogens in the fluoroarene substrates in terms of $\mathrm{p} K_{\mathrm{a}}$ values (29.0 and 31.5 for $\mathrm{C}_{6} \mathrm{~F}_{5} \mathrm{H}$ and $\mathrm{C}_{6} \mathrm{~F}_{3} \mathrm{H}_{3}$, respectively). ${ }^{[34]}$ This reactivity pattern is usually associated to main group polar organometallics such as organolithium reagents, however here, the metallation is ultimately delivered by the transition metal, yielding ferration products $\mathbf{2}$ and $\mathbf{3}$.

\section{Conclusions}

By isolating and structurally defining lithium ferrate $\mathbf{1}$ and its metallation products $\mathbf{2}$ and $\mathbf{3}$, we report a new bimetallic approach which enables the regioselective functionalisation of fluoroarenes via $\mathrm{Fe}-\mathrm{H}$ exchange reactions. While deprotonation of fluoroarenes using conventional lithium bases can be challenging due to the exceptionally fragility of the generated intermediates, these lithium-mediated ferrations occur regioselectively at room temperature affording thermally stable products. By comparison with previous work using sodium ferrates, insights into the effects of the alkali-metal have been realised which affect both the structure and reactivity of the mixed-metal species involved in these transformations. Collectively these findings open new ground towards designing new synthetic strategies for fluoroarene functionalisation by exploiting the synergic partnership of $\mathrm{Li}$ and $\mathrm{Fe}$ when both metals are integrated within the same molecular scaffold.

\section{Supplementary Information}

Supplementary information is available on https://www.ingentaconnect.com/content/scs/chimia

\section{Acknowledgements}

The X-ray crystal structure determination service unit of the Department of Chemistry and Biochemistry of the University of Bern is acknowledged for measuring, solving, refining and summarising the structure of compound 2. The Synergy diffractometer was partially funded by the Swiss National Science Foundation (SNF) within the R'Equip programme (project number 206021_177033). We also thank the University of Bern for financial support.
[1] V. Snieckus, Chem. Rev. 1990, 90, 879.

[2] C. G. Hartung, V. Snieckus, in 'Modern Arene Chemistry', Vol. 34, WileyVCH Verlag GmbH \& Co. KGaA, Weinheim, FRG, 2002, pp. 330, DOI: 10.1002/3527601767.ch10.

[3] D. W. Slocum, C. A. Jennings, J. Org. Chem. 1976, 41, 3653.

[4] T. K. Macklin, V. Snieckus, Org. Lett. 2005, 7, 2519.

[5] U. Wietelmann, J. Klett, Zeitschr. Anorg. Allg. Chem. 2018, 644, 194.

[6] R. E. Mulvey, S. D. Robertson, Angew. Chem. Int. Ed. 2013, 52, 11470.

[7] M. Schlosser, Angew. Chem. Int. Ed. 2005, 44, 376.

[8] J. Clayden, 'Organolithiums: Selectivity for Synthesis', Elsevier, Oxford, United Kingdom, 2002.

[9] L. Gupta, A. C. Hoepker, K. J. Singh, D. B. Collum, J. Org. Chem. 2009, 74, 2231.

[10] M. Schlosser, L. Guio, F. Leroux, J. Am. Chem. Soc. 2001, 123, 3822.

[11] J. Wang, M. Sánchez-Roselló, J. L. Aceña, C. del Pozo, A. E. Sorochinsky, S. Fustero, V. A. Soloshonok, H. Liu, Chem. Rev. 2014, 114, 2432.

[12] M. F. Kuehnel, D. Lentz, T. Braun, Angew. Chem. Int. Ed. 2013, 52, 3328.

[13] Y. Kondo, M. Shilai, M. Uchiyama, T. Sakamoto, J. Am. Chem. Soc. 1999, 121,3539

[14] L. Davin, R. McLellan, A. R. Kennedy, E. Hevia, Chem. Commun. 2017, 53, 11650

[15] S. D. Robertson, M. Uzelac, R. E. Mulvey, Chem. Rev. 2019, 119, 8332.

[16] M. Uzelac, R. E. Mulvey, Chem. Eur. J. 2018, 24, 7786.

[17] R. McLellan, M. Uzelac, A. R. Kennedy, E. Hevia, R. E. Mulvey, Angew. Chem. Int. Ed. 2017, 56, 9566.

[18] S. H. Wunderlich, P. Knochel, Angew. Chem. Int. Ed. 2009, 48, 9717.

[19] R. A. Andersen, K. Faegri, J. C. Green, A. Haaland, M. F. Lappert, W. P. Leung, K. Rypdal, Inorg. Chem. 1988, 27, 1782.

[20] M. Westerhausen, W. Schwarz, Zeitschr. Anorg. Allg. Chem. 1992, 609, 39.

[21] L. C. H. Maddock, T. Nixon, A. R. Kennedy, M. R. Probert, W. Clegg, E. Hevia, Angew. Chem. Int. Ed. 2018, 57, 187.

[22] L. C. H. Maddock, T. Cadenbach, A. R. Kennedy, I. Borilovic, G. Aromí, E. Hevia, Inorg. Chem. 2015, 54, 9201.

[23] S. N. König, D. Schneider, C. Maichle-Mössmer, B. M. Day, R. A. Layfield, R. Anwander, Eur. J. Inorg. Chem. 2014, 4302.

[24] R. E. Mulvey, Chem. Commun. 2001, 1049.

[25] C. F. Macrae, I. Sovago, S. J. Cottrell, P. T. A. Galek, P. McCabe, E. Pidcock, M. Platings, G. P. Shields, J. S. Stevens, M. Towler, P. A. Wood, J. Appl. Crystallogr. 2020, 53, 226.

[26] D. F. Evans, J. Chem. Soc. 1959, 2003.

[27] E. M. Schubert, J. Chem. Ed. 1992, 69, 62.

[28] C. Piguet, J. Chem. Ed. 1997, 74, 815.

[29] D. L. J. Broere, I. Čorić, A. Brosnahan, P. L. Holland, Inorg. Chem. 2017, 56, 3140.

[30] L. C. H. Maddock, I. Borilovic, J. McIntyre, A. R. Kennedy, G. Aromí, E. Hevia, Dalton Trans. 2017, 46, 6683.

[31] O. Eisenstein, J. Milani, R. N. Perutz, Chem. Rev. 2017, 117, 8710.

[32] J. Vela, J. M. Smith, Y. Yu, N. A. Ketterer, C. J. Flaschenriem, R. J. Lachicotte, P. L. Holland, J. Am. Chem. Soc. 2005, 127, 7857.

[33] X. Xu, H. Sun, Y. Shi, J. Jia, X. Li, Dalton Trans. 2011, 40, 7866.

[34] K. Shen, Y. Fu, J.-N. Li, L. Liu, Q.-X. Guo, Tetrahedron 2007, 63, 1568.

\section{License and Terms}

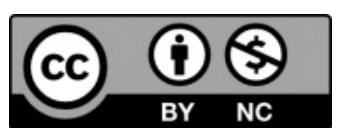

This is an Open Access article under the terms of the Creative Commons Attribution License CC BY_NC 4.0. The material may not be used for commercial purposes.

The license is subject to the CHIMIA terms and conditions: (http:// chimia.ch/component/sppagebuilder/?view=page \&id=12).

The definitive version of this article is the electronic one that can be found at https://doi.org/10.2533/chimia.2020.866 